University of Wollongong

Research Online

Australian Institute for Innovative Materials -

Papers

Australian Institute for Innovative Materials

$1-1-2012$

\title{
A multimodal optical and electrochemical device for monitoring surface reactions: Redox active surfaces in porous silicon Rugate filters
}

\author{
Simone Ciampi \\ University of New South Wales, sciampi@uow.edu.au \\ Bin Guan \\ University of New South Wales \\ Nadim A. Darwish \\ University of New South Wales, nadimdarwish@gmail.com \\ Ying Zhu \\ University of New South Wales \\ Peter J. Reece \\ University of New South Wales
}

See next page for additional authors

Follow this and additional works at: https://ro.uow.edu.au/aiimpapers

Part of the Engineering Commons, and the Physical Sciences and Mathematics Commons

Research Online is the open access institutional repository for the University of Wollongong. For further information contact the UOW Library: research-pubs@uow.edu.au 


\title{
A multimodal optical and electrochemical device for monitoring surface reactions: Redox active surfaces in porous silicon Rugate filters
}

\begin{abstract}
Herein, mesoporous silicon (PSi) is configured as a single sensing device that has dual readouts; as a photonic crystal sensor in a Rugate filter configuration, and as a high surface area porous electrode. The as-prepared PSi is chemically modified to provide it with stability in aqueous media and to allow for the subsequent coupling of chemical species, such as via $\mathrm{Cu}(\mathrm{i})$-catalyzed cycloaddition reactions between 1-alkynes and azides ("click" reactions). The utility of the bimodal capabilities of the PSi sensor for monitoring surface coupling procedures is demonstrated by the covalent coupling of a ferrocene derivative, as well as by demonstrating ligand-exchange reactions (LER) at the PSi surface. Both types of reactions were monitored through optical reflectivity measurements, as well as electrochemically via the oxidation/reduction of the surface tethered redox species. 2012 the Owner Societies.
\end{abstract}

\section{Keywords}

active, rugate, silicon, filters, multimodal, optical, surfaces, electrochemical, porous, device, monitoring, surface, reactions, redox

\section{Disciplines}

Engineering | Physical Sciences and Mathematics

\section{Publication Details}

Ciampi, S., Guan, B., Darwish, N. A., Zhu, Y., Reece, P. J. \& Gooding, J. Justin. (2012). A multimodal optical and electrochemical device for monitoring surface reactions: Redox active surfaces in porous silicon Rugate filters. Physical Chemistry Chemical Physics, 14 (47), 16433-16439.

\section{Authors}

Simone Ciampi, Bin Guan, Nadim A. Darwish, Ying Zhu, Peter J. Reece, and J Justin Gooding 


\title{
A multimodal optical and electrochemical device for monitoring surface reactions: redox active surfaces in porous silicon Rugate filters
}

\author{
Simone Ciampi, ${ }^{a}$ Bin Guan, ${ }^{a}$ Nadim A. Darwish, ${ }^{a}$ Ying Zhu, ${ }^{a}$ Peter J. Reece ${ }^{b}$ and \\ J. Justin Gooding $* a$
}

Received 1st October 2012, Accepted 22nd October 2012

DOI: $10.1039 / \mathrm{c} 2 \mathrm{cp} 43461 \mathrm{j}$

Herein, mesoporous silicon (PSi) is configured as a single sensing device that has dual readouts; as a photonic crystal sensor in a Rugate filter configuration, and as a high surface area porous electrode. The as-prepared PSi is chemically modified to provide it with stability in aqueous media and to allow for the subsequent coupling of chemical species, such as via $\mathrm{Cu}(\mathrm{I})$-catalyzed cycloaddition reactions between 1-alkynes and azides ("click" reactions). The utility of the bimodal capabilities of the PSi sensor for monitoring surface coupling procedures is demonstrated by the covalent coupling of a ferrocene derivative, as well as by demonstrating ligand-exchange reactions (LER) at the PSi surface. Both types of reactions were monitored through optical reflectivity measurements, as well as electrochemically via the oxidation/reduction of the surface tethered redox species.

\section{Introduction}

A sensor requires two essential components; a recognition interface to give the sensor its selectivity toward the analyte of interest, and a transducing component which in turns reports to the end user on the extent of the recognition event. ${ }^{1}$ Traditionally, the transducer provides a single type of signal, with either optical or electrochemical being the most popular outputs. However, there are times where multiple different types of transduction signals would provide a far greater amount of analytical information. For example, the combination of an optical reflectivity device and an electrode surface has the capability of providing optical information on the kinetics of binding events, while electrochemical measurements of the charge passed could be used to correlate optical data with the exact number of molecules bound to the surface. Herein we present a dual optical/electrochemical transducer we have developed which provides two types of optical readouts, reflectivity and infrared spectroscopy, as well as providing electrochemical information. As we are interested in developing surfaces with multiple different readouts to monitor and follow surface reactions, the capabilities of this multimodal transducer are here demonstrated for surface derivatizations, but could also be applied to many other types of sensing applications.

Surface reactions at monolayers are the basis of the fabrication of many devices; they are vital in catalysis, sensing and

\footnotetext{
${ }^{a}$ School of Chemistry and Australian Centre for Nanomedicine, University of New South Wales, Sydney 2052, Australia.

E-mail: justin.gooding@unsw.edu.au; Fax: +6129385 6141;

Tel: + 6193855384

${ }^{b}$ School of Physics, University of New South Wales, Sydney 2052,

Australia
}

studies of interfaces in general. ${ }^{2}$ One of the issues in monitoring and understanding surface reactions is the small amount of material that is present to be measured. Porous materials with high surface area could, to some degree, alleviate this issue. An important step in further understanding surface reactions is therefore to develop tools that can provide multiple types of information about the chemical process under investigation. Herein we report our initial investigations, within this regard, on the use of high surface area mesoporous silicon photonic crystals that are infrared transparent and at the same time can serve as electrodes.

Porous silicon (PSi) was chosen for this purpose for a number of reasons. First, it can be easily micro-machined electrochemically, with a high degree of control over pore size, ${ }^{3}$ into well defined photonic crystals that exhibit sharp optical reflectivity bands. ${ }^{4}$ The optical properties of the photonic crystal relate to its average refractive index, and as such, PSi can be used as a label-free optical sensor. ${ }^{5}$ Second, the process of fabricating these photonic crystals results in a high surface area mesoporous material. Third, porous silicon can also serve as an electrode material, which we have recently reported can have surprisingly low interfacial charging capacitance, ${ }^{6}$ a factor which is important in giving the electrode good analytical performances. ${ }^{7}$ Fourth, at lower doping levels PSi is IR transparent which means transmission mode FTIR spectroscopy can be performed. ${ }^{5 c}$ Finally, and perhaps most importantly, the organic modification of silicon is of enormous interest for a whole range of applications such as molecular electronics, ${ }^{8}$ molecular memories, ${ }^{9}$ optoelectronic circuitry, ${ }^{3 b}$ MEMS-compatible hybrid materials ${ }^{10}$ and biological interfaces. ${ }^{5 e, 11}$

To exploit the above features of PSi, however, first requires the as-prepared hydrogenated silicon surface to be stabilized 
via surface modification. ${ }^{4 c}$ The formation of molecular layers on $\mathrm{Si}-\mathrm{H}_{x}$ surfaces using 1-alkenes and 1-alkynes gives robust and well-defined layers on the Si surface with no intervening oxides. ${ }^{10 a, 12}$ Recent research suggests that 1-alkynes, resulting in a 1-en-1-yl silyl $(\mathrm{Si}-\mathrm{C}=\mathrm{C})$ linkage, ${ }^{13}$ give more stable, densely packed and faster forming organic monolayers compared to 1-alkenes. ${ }^{14}$ Furthermore, we have recently shown that the thermal modification of hydrogen terminated $\mathrm{Si}(100)$ and PSi photonic crystals using 1,8 -nonadiyne $\mathbf{1}^{15}$ protects the underlying silicon from oxidation even in aqueous electrolytes under the influence of oxidizing anodic potentials. ${ }^{11,16}$ The resultant acetylene-terminated PSi surface can then be reacted with a broad range of aryl and alkyl azides, ${ }^{17}$ or 1 -alkynes ${ }^{18}$ to allow for further functionalization.

The purpose of the present paper is to demonstrate the potential of using modified PSi as a multimodal electrochemical and optical device for monitoring surface reactions. In this multimodal PSi structure, the entire porous matrix (here up to $\sim 3000$ times larger than that of a crystalline $\mathrm{Si}(100)$ electrode of the same geometric area) participates in both amperometric and optical responses. The PSi photonic crystal is in this case structured as a Rugate filter. The analytical power of electrochemical methods can thus be combined with both the labelfree interrogation of the PSi sample by optical reflectivity and with the ability of FTIR spectroscopy to probe changes in chemical functionality accompanying surface reactions. The chemical reactions explored are the covalent bond-forming reaction of ferrocene derivatives to a surface and a ligand-exchange reaction (LER) scheme between tethered pyridine ligands and osmium complexes.

\section{Experimental section}

\section{Materials}

All solvents and reagents were of analytical grade and were used as received, unless otherwise noted. Chemicals used in surface modification procedures and electrochemical experiments were of high purity (>99\%). 1,8-Nonadiyne (1, Alfa Aesar, 97\%) was distilled from sodium borohydride under reduced pressure and stored under a dry argon at room temperature. Azidomethylferrocene 2 was synthesized as previously reported. ${ }^{16 b}$ The synthetic procedure for the preparation of 3-azidopropyl isonicotinate $\mathbf{3}$ in three steps from commercially available isonicotinic acid has been detailed in a previous report. ${ }^{11}$ Synthesis of Os(bpy $)_{2} \mathrm{Cl}_{2} \mathbf{4}$ followed the method of Leech and co-workers. ${ }^{19}$ Dichloromethane, ethanol, 2-propanol for surface cleaning and surface modification were redistilled prior to use. Single-side polished silicon wafers of prime grade, (100)-oriented $\left(\langle 100\rangle \pm 0.05^{\circ}\right.$ ), p-type (boron), $0.07 \Omega \mathrm{cm}, 525 \pm 25 \mu \mathrm{m}$ thick were obtained from Siltronix, S.A.S. (Archamps, France).

\section{Porous silicon fabrication}

Mesoporous silicon has been formed by electrochemical etching of Si substrates with hydrofluoric acid (HF, 48\%): absolute ethanol $(1: 1)$ as electrolyte. The preparation of porous silicon filters for reflection interference has been reported in several publications. ${ }^{4 a, 5 e, 15 b}$ Anodization was performed at room temperature in the dark under galvanostatic conditions in an open anodization cell with an o-ring seal ( $c a .0 .33 \mathrm{~cm}^{2}$ active area). A planar steel electrode pressed onto the sample backside served as an ohmic contact. A ring-shaped Pt counter electrode (cathode) was used to ensure a homogeneous electric field. Etching conditions were: (i) low porosity layer (L), $15 \mathrm{~mA} \mathrm{~cm}{ }^{-2}$, etch time: $6.0 \mathrm{~s}$; (ii) high porosity layer $(\mathrm{H})$, $36 \mathrm{~mA} \mathrm{~cm}^{-2}$, etch time: $1.6 \mathrm{~s}$. As slight local changes of the HF concentration can induce a local variation of the porosity, diffusion of the electrolyte at the dissolution front was ensured by interrupting the etch process several times during the formation of each layer $\left(3 \times 5 \mathrm{~s}\right.$ etch stops). Estimated ${ }^{20}$ porosity/thickness values are: (a) (LH): 49\%/51 nm for (L), and 54\%/91 nm for (H); (b) (LH)20: 49\%/50 nm for (L), and 54\%/91 nm for (H); (c) (LH)60: 49\%/52 nm for (L), and 54\%/ $91 \mathrm{~nm}$ for $(\mathrm{H})$. After anodization the samples were rinsed in ethanol, and then dried under nitrogen gas.

\section{Porous silicon derivatization}

Assembly of the acetylenylated PSi surface by covalent attachment of the diyne $\mathbf{1}$ followed a previously reported thermal procedure. ${ }^{15}$ After modification, the PSi samples were rinsed several times with dichloromethane and rested in dichloromethane for $12 \mathrm{~h}$ at $4{ }^{\circ} \mathrm{C}$, before being either analyzed or further reacted. CuAAC attachment of ferrocene 2 (SAM-2) and of the isonicotinic acid derivative 3 (SAM-3) to the acetylenyl surface (SAM-1) followed published procedures with minor modification. ${ }^{11,16 a}$ In brief, to a reaction vial containing the alkyne-functionalized silicon surface (SAM-1) were added (i) the azide molecule (2-3, $3 \mathrm{mM}, 2$-propanol/ water, $2: 1$ ), (ii) copper(II) sulfate pentahydrate (2 mol\% relative to the azide), (iii) sodium ascorbate $(60 \mathrm{~mol} \%$ relative to the azide), and (iv) $N, N, N^{\prime}, N^{\prime}$-tetramethylethane-1,2-diamine ( $0.5 \mathrm{~mol} \%$ relative to the azide). Reactions were carried out at room temperature, in the dark without excluding air from the reaction environment and stopped after $24 \mathrm{~h}$ by removal of the modified sample from the reaction vessel. The prepared surfacebound [1,2,3]-triazoles samples (SAM-2 and SAM-3) were rinsed consecutively with copious amounts of Milli- $\mathrm{Q}^{\mathrm{TM}}$ water and ethanol, and then rested at room temperature for a 12 hour period in a $0.05 \%(\mathrm{w} / \mathrm{v})$ ethylenediaminetetraacetic acid solution ( $\mathrm{pH}$ 7.4). Samples were then rinsed with copious amounts of Milli- $\mathrm{Q}^{\mathrm{TM}}$ water before being analyzed or further reacted. The coordination of $\mathrm{Os}(\mathrm{bpy})_{2} \mathrm{Cl}_{2} 4$ onto the isonicotinic acid modified electrodes (SAM-3) followed a procedure analogous to that of Meyer and co-worker for the ligand substitution of a chloride in the complex 4 by 4-(aminomethyl)pyridine in refluxing ethylene glycol. ${ }^{21}$ In brief, the modified silicon surface (SAM-3) was immersed in a degassed (purged with argon gas) solution of Os-complex (4,10 mM, ethylene glycol). The solution was heated at $150{ }^{\circ} \mathrm{C}$ for $2 \mathrm{~h}$. The electrode (SAM-4) was then removed from the solution and rinsed with ethanol and Milli- $\mathrm{Q}^{\mathrm{TM}}$ water before analysis.

\section{Electrochemical measurements}

Cyclic voltammetry (CV) measurements were performed using a BAS 100B electrochemical analyzer (Bioanalytical Systems, Inc., W. Lafayette, IN). Three-terminal measurements were carried out in air using a three-electrode system in either $1.0 \mathrm{M}$ 
perchloric acid (SAM-2) or 0.1 M potassium chloride (SAM-4) electrolyte solutions, with silver/silver chloride in $3 \mathrm{M}$ sodium chloride as the reference electrode, a platinum mesh (ca. $1500 \mathrm{~mm}^{2}$ ) as the counter electrode, and the functionalized PSi sample as the working electrode. Gallium-indium eutectic was applied to form a rear ohmic contact to the silicon wafers. A rectilinear cross-section gasket defined the geometric area of the working electrode to $24.6 \mathrm{~mm}^{2}$. All potentials are reported versus the reference electrode.

\section{Spectroscopy and microscopy}

X-ray photoelectron spectroscopy (XPS) measurements were performed on an ESCALAB 220iXL. Monochromatic Al K $\alpha$ $\mathrm{X}$-rays $(1486.6 \mathrm{eV})$ incident at $58^{\circ}$ to the analyzer lens were used to excite electrons from the sample. Emitted photoelectrons were collected on a hemispherical analyzer with multi-channel detector at a takeoff angle of $90^{\circ}$ from the plane of the sample surface. The analyzing chamber operated below $10^{-9} \mathrm{mbar}$ and the spot size was approximately $1 \mathrm{~mm}^{2}$. The resolution of the spectrometer was $\sim 0.6 \mathrm{eV}$. All energies are reported as binding energies in $\mathrm{eV}$ and referenced to the $\mathrm{C} 1 \mathrm{~s}$ signal (corrected to $285.0 \mathrm{eV}$ ). Survey scans were carried out selecting $100 \mathrm{~ms}$ dwell time and analyzer pass energy of $100 \mathrm{eV}$. High-resolution scans were run with $0.1 \mathrm{eV}$ step size, dwell time of $100 \mathrm{~ms}$ and the analyzer pass energy set to $20 \mathrm{eV}$. After background subtraction using the Shirley routine, spectra were fitted with a convolution of Lorentzian and Gaussian profiles as described previously. ${ }^{15 a}$ Reflectivity spectra were measured by illuminating the sample with a focused halogen light and recording data with a silicon CCD array (USB2000 ${ }^{+}$spectrometer ${ }^{\mathrm{TM}}$, Ocean Optics Inc., USA). The illumination and detection of the reflected light was performed at an angle of $0^{\circ}$ to the surface normal. Spectral resolution was $c a .1 \mathrm{~nm}$, and the spot size in the measurements was approximately $0.1 \mathrm{~mm}$ across. ThermoNicolet AVATAR 370-FTIR spectrometer, fitted with a deuterate triglycine sulphate (DTGS) detector, was used to collect the porous silicon spectra in air in normal transmission geometry, and referenced to the clean wafer transmission. Three hundred scans were accumulated with a typical spectral resolution of $4 \mathrm{~cm}^{-1}$. Scanning electron micrographs were taken using a Hitachi S900 SEM with a $4 \mathrm{kV}$ field emission source.

\section{Results and discussion}

\section{Preparation and characterization of PSi optical filters}

The specific morphology of the PSi film depends on the anodization conditions and substrate doping (type and level). ${ }^{22}$ PSi Rugate filters consists of repeated quarter wave layers with alternating high- and low-refraction indexes ( $\mathrm{H}$ and $\mathrm{L}$ hereafter) which correspond with low and high porosity silicon. Porosity values of the samples used in this study varied between $49 \%$ and $54 \%$ (see Experimental section). The thickness of the PSi films used was in the range of $1.0-9.0 \mu \mathrm{m}$ (Fig. 1), ${ }^{23}$ and pore diameters were in the range of 5-20 nm. ${ }^{6}$ The high-reflection wavelength can vary over a wide range and depends on both the thickness and refraction index contrast of the alternating $\mathrm{H}$ and $\mathrm{L}$ layers. As is shown in Fig. 1, an increase in the overall thickness of the porous film, and hence the number of alternating $\mathrm{H}$ and $\mathrm{L}$ layers,

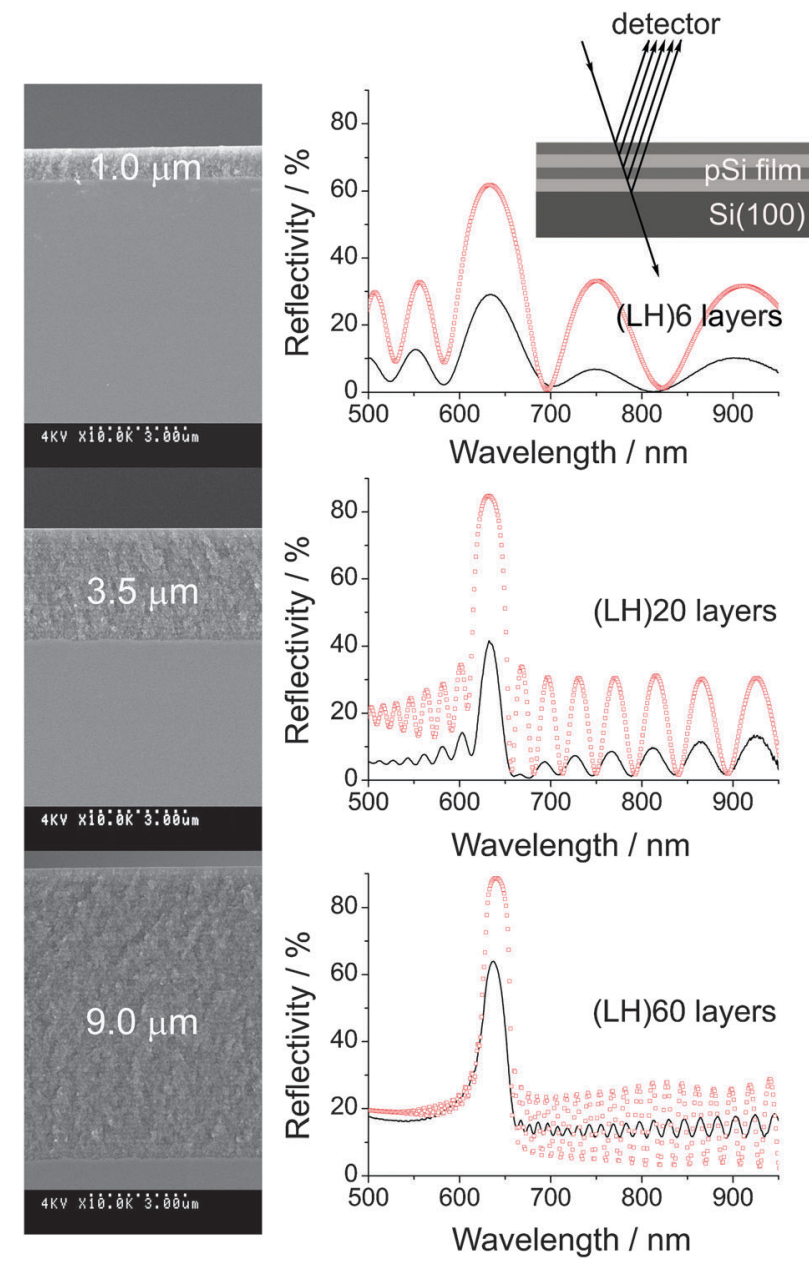

Fig. 1 Cross-section SEM micrographs and optical reflectivity spectra (-) for as-prepared $\left(\mathrm{Si}-\mathrm{H}_{x}\right)$ PSi Rugate filters. Hollow-squares lines show simulated reflectivity spectra ( $\square \square \square)$.

results in an increased reflectivity maxima. ${ }^{24}$ By comparing measured and simulated reflectivity data (i.e., position of the reflectivity maxima and fringe spacing in the low background reflectivity) the thickness of the entire structure and the individual refractive indexes of $\mathrm{H}$ and $\mathrm{L}$ layers can be estimated. The PSi film thickness values estimated from the refined reflectivity data ((LH)6: $0.85 \mu \mathrm{m}$; (LH)20: $2.8 \mu \mathrm{m}$; (LH)60: $8.6 \mu \mathrm{m}$ ) are in good agreement with values obtained from SEM micrographs (Fig. 1, left panel). The discrepancy between the measured and simulated spectra in the figure arises because the effective medium approximation used in the simulation does not take into account the contribution of absorption. Absorption in low loss structures has a minor effect on the spectral peak positions, but will influence the peak height of the reflectivity and fringe contrast.

\section{Demonstration of using PSi multimodal detectors to monitor covalent coupling reactions at surfaces}

In the first application of PSi photonic crystals as multimodal transducers for monitoring surface reactions we demonstrate the modification of freshly prepared PSi with diyne $\mathbf{1}$, followed by the coupling of azidomethylferrocene $\mathbf{2}$ onto the modified-PSi surface using "click" copper(I)-catalyzed alkyne-azide cycloaddition reactions $\left(\mathrm{CuAAC}^{25}\right){ }^{5 e, f, 16 c}$ The reaction scheme is shown in Fig. 2 
along with the FTIR, reflectivity and electrochemical characterization of the surface coupling reactions. We have recently reported the modification of PSi with this same surface chemistry to allow the PSi to be used as a high surface area and low capacitance electrode. ${ }^{6}$ As we characterized the surface chemistry using XPS, FTIR spectroscopy and electrochemistry in that previous report, here we will concentrate our discussion on the reflectivity measurements shown in Fig. 2.

During each step in the surface modification, from the addition of the diyne $\mathbf{1}$ to give SAM-1 to the covalent coupling of ferrocene $\mathbf{2}$ using CuAAC reactions to give SAM-2, we observed a red shift in the reflectivity spectrum. The magnitude of the red shifts is indicative of the amount of organic matter deposited on the PSi walls. As the wavelength of the high reflectivity band is proportional to the refractive index of the layers $(n)$, a red shift in the peak wavelength is expected when organic molecules $(n \sim 1.4)$ displace the air $(n=1)$ within the pores, thereby increasing the mean refractive index of the layers. Hence, as shown in Fig. $2 b$ and d, the Rugate filter reflectivity maxima red-shifted by $53 \pm 9 \mathrm{~nm}(95 \%$ confidence limit for $9.0 \mu \mathrm{m}$ thick PSi samples) from the $\mathrm{Si}-\mathrm{H}_{x}$ to SAM-1 samples, but only by $17 \pm 4 \mathrm{~nm}$ for the attachment of the significantly smaller ferrocene $\mathbf{2}$ (SAM-2).

The changes in surface chemistry are supported by FTIR data, which are possible because we use $\mathrm{p}^{+}$silicon to generate a $\mathrm{PSi}^{26}$ filter which is transparent in the mid IR and allows conventional FTIR instrumentation to be used. ${ }^{27}$ The IR transparency enhances our ability to use this dual PSi optical and electrochemical mesoporous structure for evaluating surface reactions. It should be noted that the spectra have not been background-subtracted and hence interference fringes are dominating the spectra baselines. The important features from the FTIR spectra that confirm the formation of SAM-1 are (i) a drastic attenuation of $\mathrm{Si}-\mathrm{H}_{x}$ stretches at $c a .2100 \mathrm{~cm}^{-1}$ (Fig. 2a) and (ii) the appearance of a number of absorbance bands related to grafted species, ${ }^{28}$ including $\nu(\equiv \mathrm{C}-\mathrm{H})$, $\nu_{\mathrm{a}}\left(\mathrm{CH}_{2}\right), \nu_{\mathrm{s}}\left(\mathrm{CH}_{2}\right), \nu(\mathrm{Si}-\mathrm{C}=\mathrm{C})$, and $\delta\left(\mathrm{CH}_{2}\right)$ modes at 3314 , 2930, 2855, 1598, and $1449 \mathrm{~cm}^{-1}$ (Fig. 2c). Upon further reaction to produce SAM-2 samples (Fig. 2f) the prominent alkyne stretch $\left(\equiv \mathrm{C}-\mathrm{H}, 3314 \mathrm{~cm}^{-1}\right)$ of the terminal alkyne

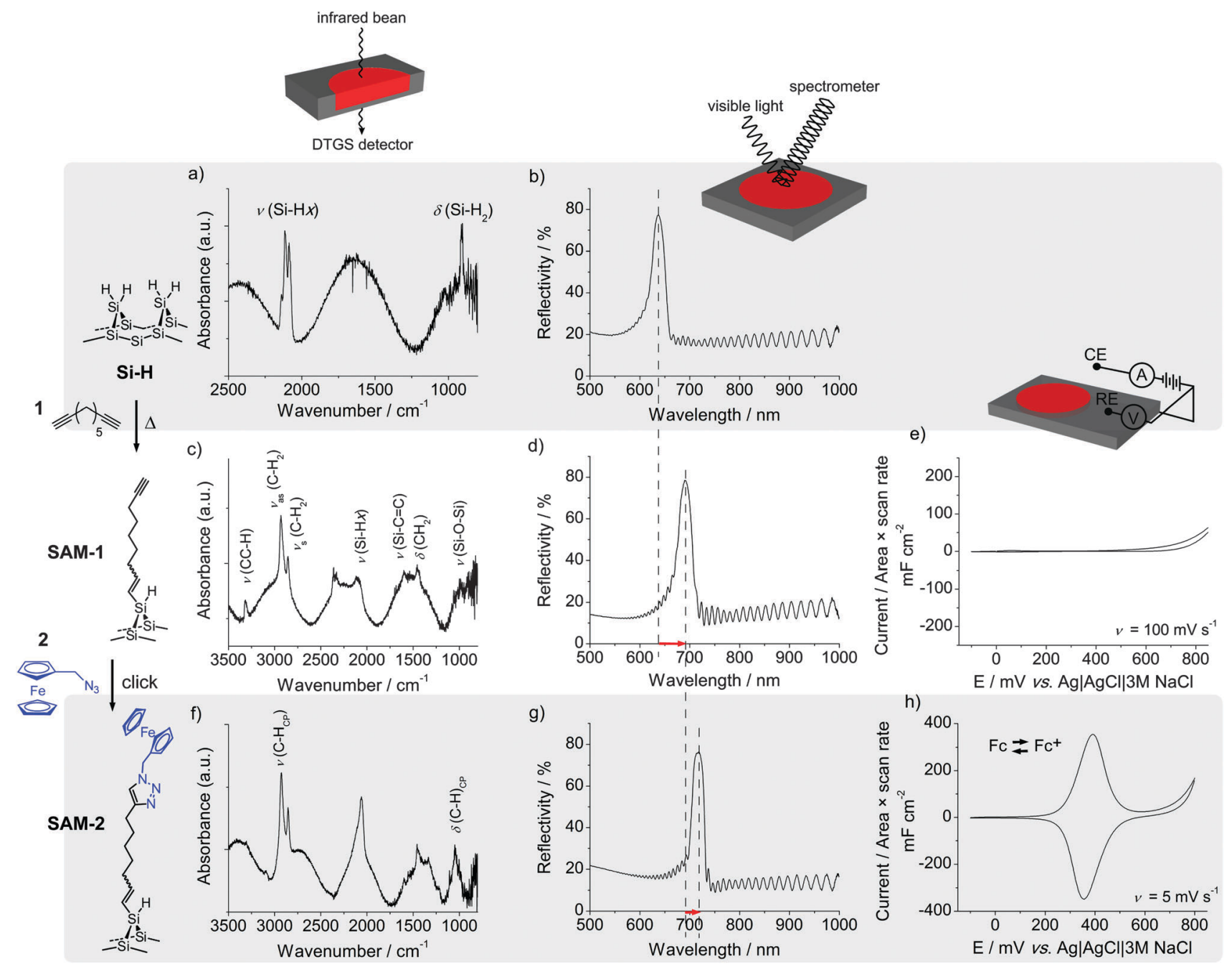

Fig. 2 Multimode Rugate filters - FTIR, optical reflectivity and electrochemical responses of PSi films. The metastable hydride-terminated PSi surface is reacted with neat $\alpha, \omega$-diacetylene species $\mathbf{1}$ to replace $\mathrm{Si}-\mathrm{H}$ with stable and non polar $\mathrm{Si}-\mathrm{C}$ bonds $(\mathbf{S A M}-\mathbf{1})$. Terminal $\equiv \mathrm{C}-\mathrm{H}$ groups (SAM-1) are used as the dipolarophile in the preparation of surface-bound 1,4-disubstituted [1,2,3]-triazoles (SAM-2) via CuAAC reactions with the azide-tagged redox molecule $\mathbf{2}$. 
group in SAM-1 samples is significantly attenuated and ring modes at $3090 \mathrm{~cm}^{-1}\left((\mathrm{C}-\mathrm{H})_{\mathrm{CP}}\right.$ stretching $)$ and $1050 \mathrm{~cm}^{-1}\left((\mathrm{C}-\mathrm{H})_{\mathrm{CP}}\right.$ in plane bending $)^{29}$ associated with the cyclopentadienyl ligands in 2 appear.

Also shown in Fig. 2 is the electrochemical analysis of the PSi structures during the modification process. The freshly prepared PSi is not subject to any electrochemical interrogation because it would oxidize in the aqueous electrolyte employed. Once chemically modified (SAM-1) the PSi electrode showed no significant Faradaic process as there is no redox species present (Fig. 2e). More significantly, the absence of Faradaic signatures when scanned to positive potentials also provides good evidence that SAM-1 is protecting the PSi matrix from oxidation. Hence, any subsequent electrochemistry observed upon coupling the ferrocene $\mathbf{2}$ onto to the PSi to give SAM-2 can be associated with the reversible oxidation/reduction of tethered ferrocene species. As can be seen in Fig. $2 \mathrm{~h}$ a very prominent Faradaic signal is observed upon coupling of the ferrocene molecule onto the PSi surface. The peak currents in the cyclic voltammograms (CV) were found to scale linearly with the potential scan rate, $\nu$, which is indicative of the ferrocene being surface-bound as suggested by the reflectivity and FTIR measurements. The half wave potential extrapolated from $\mathrm{CV}$ taken at low scan rates, was $c a .375 \mathrm{mV}$ and in excellent agreement with literature values for other ferrocene-modified $\mathrm{Si}(100)$ and $\mathrm{Si}(111)$ planar electrodes. ${ }^{16 b, 30}$ The area under the redox waves in voltammograms can be used to estimate the surface coverage of ferrocene units, $\Gamma$. The $\Gamma$ value obtained was $4.5 \pm 0.5 \times 10^{-7} \mathrm{~mol} \mathrm{~cm}^{-2}$ (geometric area) for the $9.0 \mu \mathrm{m}$ thick SAM-2 samples. Hence, in effect, the electrochemical signature can be used to calibrate the extent of the optical shift in PSi filters.

\section{Screening ligand-exchange reactions at PSi electrodes}

Next we look at a LER at the PSi surface as, at present, characterizing LER at surfaces is relatively unexplored. From an electrochemical perspective this is partly because most often the ligand exchange step is performed prior to the attachment of the redox molecule onto the solid substrate. ${ }^{31}$ The PSi matrix may thus become a convenient test substrate material. Herein LER between tethered pyridine derivatives (SAM-3) and a redox osmium complex $\left(\mathbf{4}, \mathrm{Os}(\mathrm{bpy})_{2} \mathrm{Cl}_{2}\right.$ ) will serve as an example (see Scheme 1). We have recently reported on the use of isonicotinic acid-modified planar $\mathrm{Si}(100)$ electrodes for the direct electrochemistry of cytochrome $c,{ }^{11}$ and in a preliminary note, ${ }^{32}$ we have discussed their use in the wiring of complex $\mathbf{4}$ onto the electrode surface by displacement of a chlorine atom and insertion of a tethered pyridine ligand ( $\mathrm{R}-\mathrm{py})$.

First we characterized the formation of SAM-3. As illustrated in Fig. 3, optical reflectivity shifts and high resolution XPS measurements confirm the formation of the pyridine-ligated assembly (SAM-3) by CuAAC reactions of SAM-1 with 3-azidopropyl isonicotinate $\mathbf{3}$. The high reflectivity band red-shifts $35 \pm 11 \mathrm{~nm}$ (Fig. 3a). The deconvolution of the $\mathrm{N}$ 1s and $\mathrm{C} 1 \mathrm{~s}$ XPS peaks into its different contributions, and their quantitative analysis, has been performed in agreement with literature methods (Fig. 3b and c, respectively). ${ }^{11} \mathrm{XPS} \mathrm{N}$ 1s narrow scans were deconvoluted to account for $[1,2,3]$-triazole emissions $(\mathrm{N}-\underline{\mathrm{N}}=\underline{\mathrm{N}}$ and $\underline{\mathrm{N}}-\mathrm{N}=\mathrm{N}$,
3<smiles>NCCCOC(=O)c1ccncc1</smiles>

4

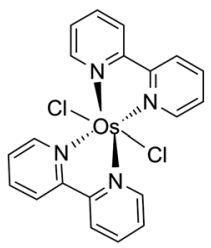

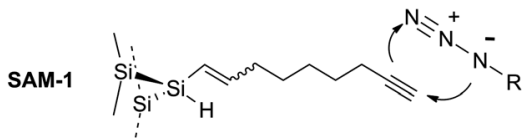

a) 3, $\mathrm{CuSO}_{4}, \mathrm{Na}$ Ascorbate iPrOH $/ \mathrm{H}_{2} \mathrm{O}$ (2:1), TMEDA, $24 \mathrm{~h}, \mathrm{RT}$ $\checkmark$ b) EDTA $0.05 \%(w / v), 12 \mathrm{~h}, \mathrm{RT}$

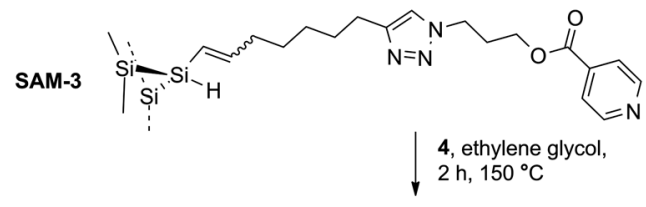

SAM-4

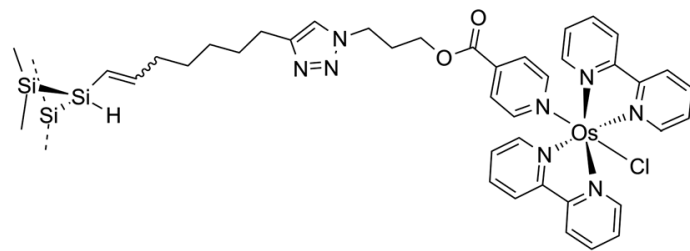

Scheme 1 Ligand exchange reactions for the coordination of $\mathrm{Os}(\mathrm{bpy})_{2} \mathrm{Cl}_{2}$ 4 onto isonicotinic acid modified PSi electrodes.

400.2 and $401.7 \mathrm{eV}$ ). Signal from the pyridine nitrogen is suggested to contribute to the $400.2 \mathrm{eV}$ peak only. The XPS C 1s region was decomposed into three functions with mean binding energies of 285.0, 286.4, and $289.7 \mathrm{eV}$. The major contribution centered at $285.0 \mathrm{eV}$ was attributed to carbon-bound carbon atoms $(\mathrm{C}-\mathrm{C})$. The peak at $286.4 \mathrm{eV}$ is characteristic of oxygen-, nitrogen-, and ester-bonded carbon atoms $(\mathrm{C}-\mathrm{O}, \mathrm{C}-\mathrm{N}$, and $\mathrm{C}(\mathrm{O}) \underline{\mathrm{C}})$. The high-energy contribution at $289.6 \mathrm{eV}$, associated
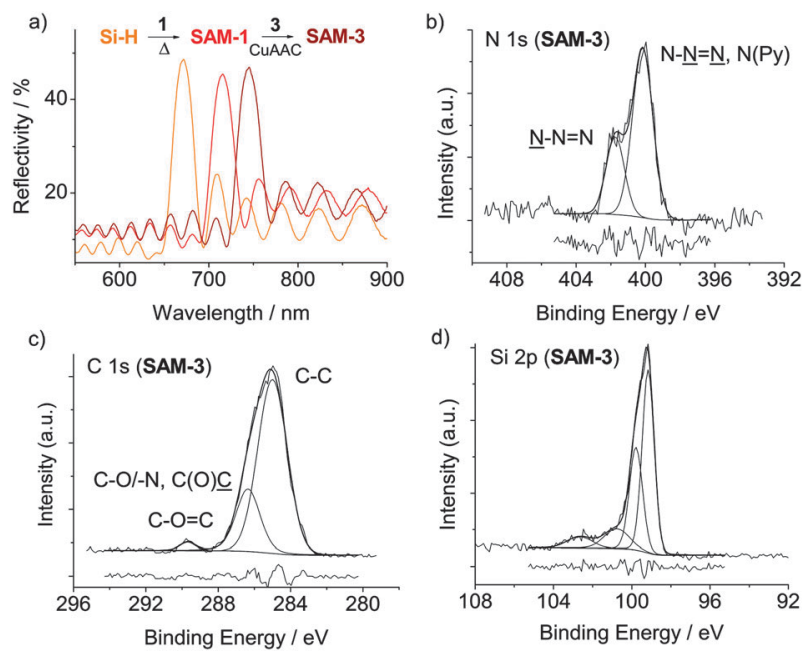

Fig. 3 Isonicotinic acid-modified PSi samples (SAM-3). (a) Optical reflectivity shifts for monolayer-modified PSi Rugate reflectors. (b) Deconvoluted XPS N 1s narrow scans. Signal from the pyridine nitrogen is suggested to contribute to the 400.2 peak. (c) XPS C 1s emission. (d) Si $2 p$ XPS region. 
a)

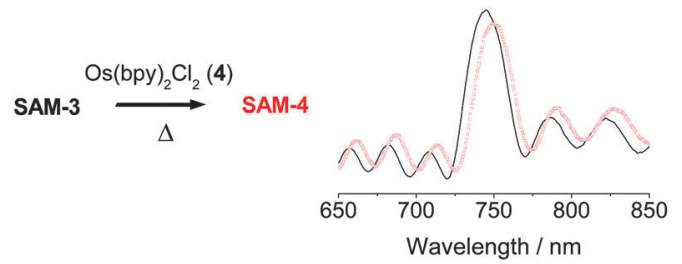

b)
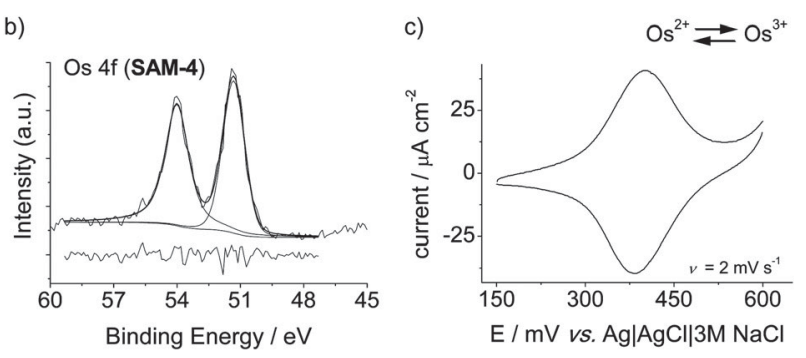

Fig. 4 (a) Evolution of the optical reflectivity spectra upon LER at immobilized pyridine ligands ( $3.5 \mu \mathrm{m}$ thick PSi layer). (b) XPS narrow scans for the Os $4 \mathrm{f}$ regions of SAM-4 samples. (c) CVs as a function of scan rate for $\mathrm{PSi} /$ isonicotinate ligands/[Os(bpy $\left.)_{2} \mathrm{Cl}\right]^{+}$systems (SAM-4). Current values are normalized to the PSi geometric area.

with the electron-deficient carbon atom in the ester carbonyl group $(\underline{\mathrm{C}}(\mathrm{O}) \mathrm{O})$ from the isonicotinic acid derivative $\mathbf{3}$.

Next, optical reflectivity, XPS and CV measurements were used to examine the ligation of the model organometallic complex $\mathbf{4}$ onto pyridine terminations of SAM-3. Fig. 4 summarizes the most relevant findings. Optical reflectivity shifts upon the formation of SAM-4 suggest a successful ligand exchange process (6 $\pm 2 \mathrm{~nm}$ red-shifted from SAM-3, Fig. 4a), and electrochemical methods aided in a more detailed quantification of the extent of conversion. Integration of the anodic and cathodic CV waves yields a $\Gamma$ value of $1.8 \pm 0.3 \times 10^{-11} \mathrm{~mol} \mathrm{~cm}^{-2},{ }^{33} \mathrm{a}$ value that is significantly lower than the maximum coverage estimated for a closed packed structure of $4\left(9 \times 10^{-11} \mathrm{~mol}\right.$ $\left.\mathrm{cm}^{-2}\right){ }^{31 a}$ The presence of appreciable repulsive lateral interactions among tethered $\mathbf{4}$ units is therefore not considered to be likely due to the small measured values of $\Gamma$. Hence it can be proposed that the observed redox centres in SAM-4 are effectively independent, i.e. nearly fully solvated by aqueous electrolytes and the local environment around each redox centre is remarkably uniform. ${ }^{34}$ The surface CVs for SAM-4 samples are in fact very close to ideal, with $\Delta E_{\mathrm{p}}$ values of $10 \mathrm{mV}$ at low $\nu$ values, and peak dispersions $\left(\Delta E_{\mathrm{fwhm}}\right)$ as low as $110 \mathrm{mV}$. Based on the consistency of the optical reflectivity and voltammetry data, our screening of a representative LER at monolayers on PSi Rugate filters shows this class of reactions is a viable approach to well-behaved redox active films.

\section{Conclusions}

Many of the factors of merit of PSi in sensing, ${ }^{4 c, 35}$ that is a large surface area, an accessible pore network, a tunable refractive index, and an expanding pool of available surface derivatization strategies, are combined when using PSi optical filters as an electrode material to give a multimodal transducer. Here it is shown using the one material that optical reflectivity, FTIR spectroscopy and cyclic voltammetry can be used to monitor surface reactions. Two classes of surface reactions are monitored; the covalent coupling of a ferrocene derivative and a ligand exchange reaction at a surface involving a redox-active osmium complex. Hence, the high surface area of PSi, combined with its optical and electrochemical characteristics, can provide an experimentally simple analytical tool kit to aid in the characterization of a monolayer at a surface. The ability to simultaneously monitor the electrochemical and optical signatures of surface reactions on these PSi substrates also provides the potential to monitor the kinetics of these surface reactions.

\section{Acknowledgements}

This research was supported by the Australian Research Council's Discovery Projects Funding Scheme. S.C. was supported by an International Postgraduate Research Scholarship from the Australian Government and by a Research Postgraduate Award from the Australian Institute of Nuclear Science and Engineering (AINSE).

\section{Notes and references}

1 (a) E. A. H. Hall, J. J. Gooding and C. E. Hall, Mikochim. Acta, 1995, 121, 119; (b) A. H. Hall Elizabeth, in Biosensors and Chemical Sensors, American Chemical Society, 1992, vol. 487, ch. 1, pp. 1.

2 (a) R. N. Dominey, N. S. Lewis, J. A. Bruce, D. C. Bookbinder and M. S. Wrighton, J. Am. Chem. Soc., 1982, 104, 467; (b) M. S. Wrighton, Science, 1986, 231, 32; (c) G. Lee, L. Chrisey and R. Colton, Science, 1994, 266, 771; (d) M. Mrksich, Curr. Opin. Chem. Biol. 2002, 6, 794; (e) A. Ulman, Chem. Rev., 1996, 96, 1533; (f) M. James, T. A. Darwish, S. Ciampi, S. O. Sylvester, Z. Zhang, A. Ng, J. J. Gooding and T. L. Hanley, Soft Matter, 2011, 7, 5309; (g) J. J. Gooding and S. Ciampi, Chem. Soc. Rev., 2011, 40, 2704.

3 (a) R. Mlcak, H. L. Tuller, P. Greiff, J. Sohn and L. Niles, Sens. Actuators, A, 1994, 40, 49; (b) O. Bisi, S. Ossicini and L. Pavesi, Surf. Sci. Rep., 2000, 38, 1.

4 (a) S. Ilyas, T. Böcking, K. A. Kilian, P. J. Reece, J. J. Gooding, K. Gaus and M. Gal, Opt. Mater., 2007, 29, 619; (b) K. A. Kilian, T. Böcking, K. Gaus, M. Gal and J. J. Gooding, ACS Nano, 2007, 1, 355; (c) K. A. Kilian, T. Böcking and J. J. Gooding, Chem. Commun., 2009, 630.

5 (a) V. S.-Y. Lin, K. Motesharei, K.-P. S. Dancil, M. J. Sailor and M. R. Ghadiri, Science, 1997, 278, 840; (b) A. Janshoff, K.-P. S. Dancil, C. Steinem, D. P. Greiner, V. S. Y. Lin, C. Gurtner, K. Motesharei, M. J. Sailor and M. R. Ghadiri, J. Am. Chem. Soc., 1998, 120, 12108; (c) K. A. Kilian, T. Böcking, S. Ilyas, K. Gaus, J. Wendy, M. Gal and J. J. Gooding, Adv. Funct. Mater., 2007, 17, 2884; (d) A. Jane, R. Dronov, A. Hodges and N. H. Voelcker, Trends Biotechnol., 2009, 27, 230; (e) B. Guan, A. Magenau, K. A. Kilian, S. Ciampi, K. Gaus, P. J. Reece and J. J. Gooding, Faraday Discuss., 2011, 149, 301; ( $f$ ) B. Guan, S. Ciampi, G. Le Saux, K. Gaus, P. J. Reece and J. J. Gooding, Langmuir, 2011, 27, 328.

6 S. Ciampi, B. Guan, N. Darwish, P. J. Reece and J. J. Gooding, J. Phys. Chem. C, 2012, 116, 16080.

7 P. R. Warburton, M. P. Pagano, R. Hoover, M. Logman, K. Crytzer and Y. J. Warburton, Anal. Chem., 1998, 70, 998.

8 A. Vilan, O. Yaffe, A. Biller, A. Salomon, A. Kahn and D. Cahen, Adv. Mater., 2010, 22, 140.

9 B. Fabre, Acc. Chem. Res., 2010, 43, 1509.

10 (a) N. Shirahata, A. Hozumi and T. Yonezawa, Chem. Rec., 2005, 5, 145; (b) W. R. Ashurst, C. Yau, C. Carraro, C. Lee, G. J. Kluth, R. T. Howe and R. Maboudian, Sens. Actuators, A, 2001, 91, 239. 11 S. Ciampi and J. J. Gooding, Chem.-Eur. J., 2010, 16, 5961.

12 (a) D. Wayner and R. Wolkow, J. Chem. Soc., Perkin Trans. 2, 2002, 23; (b) J. M. Buriak, Chem. Commun., 1999, 1051; (c) J. M. Buriak, Chem. Rev., 2002, 102, 1271; (d) R. Boukherroub, Curr. Opin. Solid State Mater. Sci., 2005, 9, 66; (e) M. R. Linford, P. Fenter, P. M. Eisenberger and C. E. D. Chidsey, J. Am. Chem. Soc., 1995, 
117, 3145; $(f)$ S. R. Puniredd, O. Assad and H. Haick, J. Am. Chem. Soc., 2008, 130, 13727; (g) A. B. Sieval, A. L. Demirel, J. W. M. Nissink, M. R. Linford, J. H. van der Maas, W. H. de Jeu, H. Zuilhof and E. J. R. Sudhölter, Langmuir, 1998, 14, 1759; (h) M. M. Sung, G. J. Kluth, O. W. Yauw and R. Maboudian, Langmuir, 1997 , 13, 6164; (i) R. J. Hamers, Annu. Rev. Anal. Chem., 2008, 1, 707.

13 C. Coletti, A. Marrone, G. Giorgi, A. Sgamellotti, G. Cerofolini and N. Re, Langmuir, 2006, 22, 9949.

14 (a) L. Scheres, A. Arafat and H. Zuilhof, Langmuir, 2007, 23, 8343; (b) L. Scheres, M. Giesbers and H. Zuilhof, Langmuir, 2010, 26, 10924; (c) D. Zigah, C. Herrier, L. Scheres, M. Giesbers, B. Fabre, P. Hapiot and H. Zuilhof, Angew. Chem., Int. Ed., 2010, 49, 3157; (d) B. Rijksen, B. van Lagen and H. Zuilhof, J. Am. Chem. Soc., 2011, 133, 4998.

15 (a) S. Ciampi, T. Böcking, K. A. Kilian, M. James, J. B. Harper and J. J. Gooding, Langmuir, 2007, 23, 9320; (b) S. Ciampi, T. Böcking, K. A. Kilian, J. B. Harper and J. J. Gooding, Langmuir, 2008, 24, 5888

16 (a) S. Ciampi, G. Le Saux, J. B. Harper and J. J. Gooding, Electroanalysis, 2008, 20, 1513; (b) S. Ciampi, P. K. Eggers, G. Le Saux, M. James, J. B. Harper and J. J. Gooding, Langmuir, 2009, 25, 2530; (c) S. Ciampi, M. James, G. Le Saux, K. Gaus and J. Justin Gooding, J. Am. Chem. Soc., 2012, 134, 844.

17 S. Ciampi, J. B. Harper and J. J. Gooding, Chem. Soc. Rev., 2010, 39, 2158.

18 S. Ciampi, M. James, N. Darwish, E. Luais, B. Guan, J. B. Harper and J. J. Gooding, Phys. Chem. Chem. Phys., 2011, 13, 15624.

19 S. Boland, F. d. r. Barriere and D. n. Leech, Langmuir, 2008, 24, 6351

20 D. A. G. Bruggeman, Ann. Phys., 1935, 416, 636.

21 E. M. Kober, J. V. Caspar, B. P. Sullivan and T. J. Meyer, Inorg. Chem., 1988, 27, 4587.

22 X. G. Zhang, S. D. Collins and R. L. Smith, J. Electrochem. Soc., 1989, 136, 1561.

23 The number of repetitions is limited because, inhomogeneities of the porous layers start to appear with increasing depth.
24 The maxima of the reflection spectra shows a decreasing reflectivity value in going from a red to a blue light. This results from the increasing absorption of light by silicon at shorter wavelengths.

25 M. Meldal and C. W. Tornøe, Chem. Rev., 2008, 108, 2952.

26 (a) P. Gupta, V. L. Colvin and S. M. George, Phys. Rev. B: Condens. Matter Mater. Phys., 1988, 37, 8234; (b) F. Ozanam, C. D. Fonseca, A. Venkateswara and R. J. N. Chazalviel, Appl. Spectrosc., 1997, 51, 519.

27 (a) D. B. Mawhinney, J. A. Glass and J. T. Yates, J. Phys. Chem. $B, 1997,101,1202$; (b) J. M. Buriak, M. P. Stewart, T. W. Geders, M. J. Allen, H. C. Choi, J. Smith, D. Raftery and L. T. Canham, J. Am. Chem. Soc., 1999, 121, 11491; (c) S. Sam, L. Touahir, J. Salvador Andresa, P. Allongue, J. N. Chazalviel, A. C. GougetLaemmel, C. Henry de Villeneuve, A. Moraillon, F. Ozanam, N. Gabouze and S. Djebbar, Langmuir, 2010, 26, 809.

28 (a) J. E. Bateman, R. D. Eagling, D. R. Worrall, B. R. Horrocks and A. Houlton, Angew. Chem., Int. Ed., 1998, 37, 2683; (b) D. Wang and J. M. Buriak, Langmuir, 2006, 22, 6214; (c) J. M. Buriak and M. J. Allen, J. Am. Chem. Soc., 1998, 120, 1339

29 J. Shimei and W. Yue, Spectrochim. Acta, Part A, 1999, 55, 1025.

30 (a) N. Tajimi, H. Sano, K. Murase, K.-H. Lee and H. Sugimura, Langmuir, 2007, 23, 3193; (b) S. Ciampi, M. James, P. Michaels and J. J. Gooding, Langmuir, 2011, 27, 6940.

31 (a) A. Ricci, C. Rolli, S. Rothacher, L. Baraldo, C. Bonazzola, E. Calvo, N. Tognalli and A. Fainstein, J. Solid State Electrochem., 2007, 11, 1511; (b) J. Hajdukiewicz, S. Boland, P. Kavanagh and D. Leech, Biosens. Bioelectron., 2010, 25, 1037.

32 S. Ciampi, L. M. H. Lai and J. J. Gooding, Silicon (100) surfaces modified by osmium bipyridine complexes, 2010, 2010 International Conference on Nanoscience and Nanotechnology (ICONN).

33 Total surface area to geometric area ratio of $c a .1130 \mathrm{~cm}^{2} / \mathrm{cm}^{2}$ (BET data).

34 (a) J. J. Calvente, R. Andreu, M. Molero, G. Lopez-Perez and M. Dominguez, J. Phys. Chem. B, 2001, 105, 9557; (b) C. E. D. Chidsey, C. R. Bertozzi, T. M. Putvinski and A. M. Mujsce, J. Am. Chem. Soc., 1990, 112, 4301

35 M. J. Sailor and J. R. Link, Chem. Commun., 2005, 1375. 